\title{
Compliance of Educational Resources with Learning Resource Management and Development System Standards
}

\author{
Ladie M. Ballesteros \\ Department of Education-Bacolod City Schools Division, Philippines \\ ladie.ballesteros@deped.gov.ph \\ https://orcid.org/0000-0002-1658-1925
}

\begin{abstract}
Adherence to standards ascertains high-quality educational resources. This descriptive-comparative research was conducted to determine the compliance level of educational resources in English with the Learning Resource Management and Development (LRMDS) standards and to identify the challenges encountered by the resource developers. Standardized LRMDS instruments were used in the evaluation of educational resources by the participants. Descriptive analysis using mean found failed compliance level in Intellectual Property Right (IPR) specification. Comparative analysis using ANOVA and t-test found significantly different compliance levels in terms of LRMDS specifications and in terms of key evaluation and assessment personnel. Apparently, variables age, tenure, educational attainment, and teaching load do not affect the compliance level. The results disclosed that the educational resources in English have weak adherence to IPR standards, which suggests that copyright compliance is the major weakness of resource developers. Hence, it is imperatively important for standards to be realistically set, and conscientiously realized.
\end{abstract}

Keywords: Education, Compliance, Educational Sources, Learning Resource Management and Development System, DescriptiveComparative, Bacolod City, Philippines 